\title{
Customer preferences using conjoint analysis: A case study of Auto industry
}

\author{
Bagher Jamali Hondori ${ }^{a^{*}}$, Hassan Javanshir ${ }^{\mathrm{b}}$ and Yousef Rabanic
}

${ }^{a}$ Department of Industrial Engineering, Science and Research Branch, Islamic Azad University, Hormozgan, Iran

${ }^{b}$ Department of Industrial Engineering, South Tehran Branch, Islamic Azad University, Tehran, Iran

${ }^{c}$ Department of Engineering, University of Hormozgan, Hormozgan, Iran

C H R O N I C LE

Article history:

Received May 22, 2013

Received in revised format

12 August 2013

Accepted 7 September 2013

Available online

September 142013

Keywords:

Conjoint analysis

Customer preferences

Auto industry

\section{A B S T R A C T}

\begin{abstract}
One of the primary concerns in product development is to meet customers' wishes and this could be accomplished through detecting the most popular characteristics of products. In other words, the fulfillment of customers' preferences in a profitable way needs that companies recognize which specifications of their product and service are most valued by the customer. Conjoint analysis is believed to be one of the most popular techniques for achieving this purpose. Conjoint analysis includes generating and conducting specific experiments among customers for modeling their purchasing decision. This paper presents an empirical investigation on detecting appropriate customer preferences in an auto-industry. The results of the survey indicate that price, braking system and having airbag are the most important characteristics for selling cars in Iranian market.
\end{abstract}

\section{Introduction}

One of the primary concerns in product development is to meet customers' wishes and this could be accomplished through detecting the most popular characteristics of products. Conjoint method has been considered as one of the most popular methods for detecting customers' preferences. Conjoint method is any de-compositional technique that estimates the structure of consumers' preferences, given their overall evaluations of a set of alternatives pre-specified in terms of levels of various attributes (Cattin \& Wittink, 1982; Green \& Snnivasan, 1990; Tempesta et al., 2010; Sáenz-Navajas et al., 2013). In this analysis, by implementing the Johnson's trade-off method to the rank orders data of preference among pairs of attributes collected from consumers, utility value for each level of each attribute is predicted. The trade-off method makes few cognitive demands on the respondent and is conductive to respondent's losing their places on the table. However, the task is unrealistic since wreak alternatives may not present themselves for evaluation on a trade-off approach basis.

*Corresponding author. Tel: +989199916637 
Literally many people have successfully used this technique; Yoo and Ohta (1994), for instance, investigated the optimal product-planning for new multi-attribute products based on the utility measures of attribute levels computed by the conjoint analysis. They applied the full-profile approach to the rank order data of preference among full-profiles collected from consumers.

Choice-based conjoint analysis (CBC) is presently the most popular kind of conjoint analysis and few alternative estimation methods have been recommended since the Hierarchical Bayes (HB) method was introduced for estimating CBC utility functions. Halme and Kallio (2011) compared the performance of 4 different optimization-based procedures and introduced a new one called CP. The $\mathrm{CPis}$ an estimation approach based on convex penalty minimization. In comparison with $\mathrm{HB}$ as the benchmark they applied eight field data sets. Noguchi and Ishii (2000) introduced some methods including MONANOVA for determining the statistical part worth value of factors in conjoint analysis. MOANOVA is used for measuring the part worth value of different factors to the total evaluation based on preference ranking data of a group of commercial products designed by presorted various factors. Moskowitz and Silcher (2006) applied the applications of conjoint analysis and their possible uses in Sensometrics.

These days, many people face an array of multi-attribute prescription benefit insurance programs, which include various access points such as retail, supermarket, Internet and levels of pharmacist interaction including medication therapy management services (MTMSs). Wellman and Vidican (2008) performed a pilot study of a hierarchical Bayes method for utility prediction in a choice-based conjoint analysis of prescription advantage plans including medication therapy management services. They performed a pilot study to detect whether choice-based conjoint (CBC) analysis with hierarchical Bayes (HB) estimation for individual level part-worth could provide a stable model for attribute preferences for prescription benefit insurance. The study also tried to pilot test the addition of MTMSs to a prescription benefit management model. They concluded that the use of CBC analysis with HB estimation could provide utilities similar to those estimated using aggregated logit-based techniques, with the added benefit of respondent specific part-worth scores for each attribute level.

\section{The proposed study}

In this paper, we present an empirical investigation to find important factors influencing customer preferences in Iranian auto industry. There are literally three different methods of Traditional, Adaptive and Choice-Based for analyzing the profile of a product. The proposed model of this paper uses traditional conjoint method to measure customer's preferences based on the following model,

$U(X)=\sum_{i=1}^{m} \sum_{j=1}^{k_{i}} a_{i j} x_{i j}$

where $U(X)$ is the overall utility (importance) of an attribute, $a_{i j}$ is part-worth utility of the $j^{\text {th }}$ level of the $i^{\text {th }}$ attribute with $i=1,2, \ldots, m$ and $j=1,2, \ldots, k_{i}$. In addition, $x_{i j}=1$, if the $j^{\text {th }}$ level of the $i^{\text {th }}$ attribute is present and 0 , otherwise. To use model (1), it is suggested that we need to apply this method based on an interview with some experts and our survey indicates that most studies use only 20-30 survey interviews. In our study, we rely on gathering the necessary information through interviewing 20 customers. We first detected 38 factors and the factors were reduced to 23 factors in our final investigation and the survey was accomplished in 7 point Likert scale. The study has detected 7 important factors as follows,

1. ABS braking system,

2. Price,

3. Strength and hardness of car against possible accidents, 
4. Hydraulic steer wheels,

5. Availability of car accessories,

6. Air bag,

7. Fuel consumption.

Since all different choices in our study have had hydraulic steer wheels, we have decided to remove this option from our list and we have replaced it with a new option on having sufficient space in car trunk for installing a new gas cylinder. Table 1 summarizes different options for the seven mentioned characteristics.

\section{Table 1}

Different characteristics

\begin{tabular}{lccclcc}
\hline Brake system & Price & Durability & Accessories & Air bag & Fuel consumption & Car trunk capacity \\
\hline No ABS & $120-155$ & $85-100$ & $15 \%$ above average & No airbag & $6-7$ & $200-300$ \\
ABS & $155-190$ & $70-85$ & $15 \%$ Average & Just for driver & $7-8$ & $300-400$ \\
ABS-EBD & $190-225$ & $55-70$ & $15 \%$ below average & For two front passengers & $8-9$ & $400-500$ \\
- & $224-260$ & $<55$ & - & For all passengers & $9-10$ & $500-600$ \\
\hline
\end{tabular}

Based on the results of Table 1, we realize that there are 9216 different options associated with the proposed study of this paper. Since it is practically impossible to consider all options, we have decided to choose the best combinations of various options. In this study, we have used Fractional Factorial Design with Orthogonal Design to choose only 32 options.

\section{The results}

In this section, we present details of our survey using XLSTAT to extract appropriate options for car selection. Table 2 summarizes the results of our survey.

\section{Table 2}

The summary of our survey

\begin{tabular}{|c|c|c|c|c|}
\hline Source & Minimum & Maximum & Mean & Std. deviation \\
\hline Intercept & 14.444 & 19.731 & 17.430 & 1.267 \\
\hline $\mathrm{ABS}$ & -1.464 & 5.333 & 1.003 & 1.457 \\
\hline ABS-EBD & -0.307 & 10.155 & 3.165 & 3.826 \\
\hline Regular brake & -11.606 & 0.185 & -4.168 & 4.574 \\
\hline Accessories more than $15 \%$ of average market & -4.263 & 9.839 & 0.265 & 1.735 \\
\hline Accessories less than $15 \%$ of average market & -11.462 & 6.391 & -0.342 & 2.023 \\
\hline Accessories are the same as existing products on the market & -6.400 & 5.426 & 0.077 & 1.625 \\
\hline Car trunk capacity is about $200-300$ litters & -3.001 & 3.185 & 0.029 & 0.862 \\
\hline Car trunk capacity is about $300-400$ litters & -3.201 & 1.334 & -0.261 & 0.790 \\
\hline Car trunk capacity is about $400-500$ litters & -1.722 & 3.226 & 0.224 & 0.917 \\
\hline Car trunk capacity is about $500-600$ litters & -3.210 & 3.001 & 0.008 & 0.979 \\
\hline Prices are between $120-155$ Million Rials & -12.387 & 12.681 & 0.837 & 5.823 \\
\hline Prices are between 155-190 Million Rials & -5.109 & 12.000 & 0.832 & 2.962 \\
\hline Prices are between 155-225 Million Rials & -6.970 & 12.006 & -0.255 & 3.392 \\
\hline Prices are between 225-260 Million Rials & -13.091 & 15.980 & -1.415 & 5.960 \\
\hline Fuel consumption is between 6-7 litres in $100 \mathrm{KM}$ & -1.523 & 15.992 & 1.565 & 2.951 \\
\hline Fuel consumption is between $7-8$ litres in $100 \mathrm{KM}$ & -5.303 & 4.239 & 0.505 & 1.363 \\
\hline Fuel consumption is between $8-9$ litres in $100 \mathrm{KM}$ & -5.331 & 4.203 & -0.476 & 1.394 \\
\hline Fuel consumption is between $9-10$ litres in $100 \mathrm{KM}$ & -12.962 & 2.348 & -1.594 & 2.788 \\
\hline Strength and durability against accidents between $55-70$ & -15.911 & 5.448 & -0.878 & 3.005 \\
\hline Strength and durability against accidents between $70-85$ & -4.652 & 7.486 & 1.116 & 2.374 \\
\hline Strength and durability against accidents between $85-100$ & -2.342 & 12.204 & 2.365 & 3.802 \\
\hline Strength and durability against accidents less than 55 & -16.507 & 4.739 & -2.603 & 4.928 \\
\hline Air bag is available only for driver & -6.118 & 4.420 & -0.677 & 1.746 \\
\hline Air bag is available for two upfront drivers & -1.786 & 8.549 & 1.087 & 2.057 \\
\hline No Air bag is available & -13.055 & 2.430 & -2.707 & 4.053 \\
\hline Air bag is available for all passengers & -0.159 & 12.387 & 2.297 & 3.257 \\
\hline
\end{tabular}




\section{Discussion and conclusion}

These days, automobile has become a necessary tool for transportation and most people prefer to have at least one car to facilitate their daily business activities such as shopping, going to work, etc. Each year, over 60 million cars are sold worldwide and demand for purchasing such product has been stable. There are different options for cars sold on the market and auto sellers need to reduce their options to more popular ones. In this paper, we have performed an empirical investigation on choosing the most suitable options, which could be offered to customers in a package. Our survey has indicated that price of a car has received the most important point (24.392) followed by braking system (20.979), strength and durability of vehicle (19.598), number of available airbags (15.429), fuel consumption (11.129), car accessories (5.124) and car trunk capacity (3.349). One primary conclusion from this survey is that price is an important part of this survey and auto industry needs to carefully optimize its cost component to provide lower costs. In addition, safety is an important issue and the industry is recommended to use ABS system in all vehicles sold on the market. Air bag is another safety system and it is recommended to all automakers to provide cars with air bag.

\section{Acknowledgment}

The authors would like to thank the anonymous referees for constructive comments on earlier version of this paper.

\section{References}

Cattin, P., \& Wittink, D. R. (1982). Commercial use of conjoint analysis: a survey. Journal of Marketing, 46, 44-53.

Green, P.E., \& Snnivasan, V. (1990). Conjoint analysis in marketing: New developments with implications for research and practice. Journal of Marketing, 54, 3-19.

Halme, M., \& Kallio, M. (2011). Estimation methods for choice-based conjoint analysis of consumer preferences. European Journal of Operational Research, 214, 160-167.

Moskowitz, H.R., \& Silcher, M. (2006). The applications of conjoint analysis and their possible uses in Sensometrics. Food Quality and Preference, 17, 145-165.

Noguchi, H., \& Ishii, H. (2000). Methods for determining the statistical part worth value of factors in conjoint analysis. Mathematical and Computer Modelling, 31, 261-271.

Yoo, D.I., \& Ohta, H. (1994). Optimal product-planning for new multiattribute products based on conjoint analysis. Computers \& Industrial Engineering, 27(1-4), 11-14.

Sáenz-Navajas, M.P., Campo, E., Sutan, A., Ballester, J., \& Valentin, J. (2013). Perception of wine quality according to extrinsic cues: The case of Burgundy wine consumers. Food Quality and Preference, 27, 44-53.

Tempesta, T., Giancristofaro, R. A., Corain, L., Salmaso, L., Tomasi, D., \& Boatto, V. (2010). The importance of landscape in wine quality perception: An integrated approach using choice-based conjoint analysis and combination-based permutation tests. Food Quality and Preference, 21(7), $827-836$.

Wellman, G. S., \& Vidican, C. (2008). Pilot study of a hierarchical Bayes method for utility estimation in a choice-based conjoint analysis of prescription benefit plans including medication therapy management services. Research in Social and Administrative Pharmacy, 4(3), 218-230. 